\title{
Role of Parental Factors in the Career Development of Children with Mild Intellectual Disabilities in Three Selected Skills Training Centres in Zambia
}

\author{
Viola Mathatha*, Professor Lufeyo Chitondo \\ Zambia \\ *Corresponding Author: Viola Mathatha, Zambia
}

\begin{abstract}
The purpose of this descriptive survey was to establish the role of parental factors in the career development of children with MIDs in three selected Skills Training Centres in Zambia. Thesamplecomprised 100 respondents: 60 parents, 30 children 6 lecturers, 3 principals and 1 Director. Purposive sampling was used to select Centres, Principals and the Director while simple random sampling was used to select lectures and children. Semi-structured interviews were administered to parents, questionnaires were administered to lecturers, Principals and the Director while Focus Group Discussions were used to collect data from children. Qualitative data was thematically analysed while scarce quantitative data was analysed using the Statistical Package of Social Sciences (SPSS). By carefully analysing the role of parental factors in the career development of children with MIDs in aspects such as interactions, role modelling and supporting children in careers, it became apparent that parents especially those with low levels of education were not inspirational to their children and they lacked knowledge on MIDs and its career implication. In addition, the low expectations parents had affected the support they rendered in their children's career development. This is attributed to lack of awareness or sensitisation. The study recommends that Skills Training Centres should help parents form or join support groups for them share experiences and increase their knowledge base. The MoHE in collaboration with the Ministry of Health $(\mathrm{MoH})$ and the Ministry of Community Development, Mother and Child Health (MCDMCH) should sensitise society on mild intellectual disabilities and its educational implications.
\end{abstract}

Keywords: Career Development, Parent, Children, Mild Intellectual Disabilities (MIDs).

\section{INTRODUCTION}

Childrenwithintellectualdisabilitieshavegeneralisedneurologicaldisorders, characterized by significan tly impaired intellectual and adaptive functioning (WHO, 2015) which inhibits them from progressing into higher grades and compete favourably with others. Before the 18th century, infants with intellectual disabilities were left to die, however, in mid-1800s, rehabilitating, training and reintegrating people with intellectual disabilities into "normal" life began through reformers, such as Dorothea Dix (Beirne-Smith, Patton \& Kim, 2006). These children can and do go on to succeed in education and employment (Asbury, 2010) as such when they attain the age of 16 or above (16+), they are trained in special vocation to equip them for employment and meaningful adult life. To this effect, the then Ministry of Science, Technology and Vocational Training formulated a policy, the Technical, Education, Vocational and Entrepreneurship Training (TEVET), to prepare all children, inclusive of those within tellectualdisabilities, for the lab our market and mutual integration into society. In spite of this effort by government, Central Statistics Office (CSO, 2012) reports that individuals with intellectual disabilities are mostly in family businesses with little or nopayat all (ibid.).

As early as 1966, parents were recognised as partners in the education of their children (MoE, 1996).The government recognises the need to collaborate with parents in the provision of any form ofeducationortraining.Consistently,studieswithhaveshownthatparentsinfluencecareerdevelopment of their children (Liu, MacMahon and Watson, 2015).Among factors that are significant in fostering or inhibiting career development are parental education, socioeconomic a status and occupation of parents (Mwaa 2016, Oluwadala, 2016). These studies however have mostly focused on children 
Role of Parental Factors in the Career Development of Children with Mild Intellectual Disabilities in Three Selected Skills Training Centres in Zambia

without MIDs. The researcher wonders how parental factors (educational level, Occupation and socioeconomic status) play a role in the career development of children with MIDs.

\subsection{Statement of the Problem}

While individual attributes such as interest, or personality, self-concept play a pivotal role in the career development of children (Kerka, 2000: Oluwadala, 2016), some studies (Whist on\& Keller, 2004: Mwaa, 2016)) show that parents factors play a role in the career development of their children without disabilities. What remains unknown is the role of parental factors in the career development of children with MIDs.

\subsection{Purpose}

The purpose was to explore the role of parental factors in the career development of children with MIDs.

\subsection{Research Objectives}

1. Toexplorehowtheeducationlevelofparentsplaysaroleinthecareerdevelopmentofchildrenwithintellec tualdisabilities

2. To determine how occupations of parents play a role in the career development of children with MIDs;

3. To establish how the socioeconomic status of parents play a role in the career development of children with MIDs.

\subsection{Theoretical Framework}

The study was guided by the Ecological Systems Theory by Urie Bronfenbrenner (1999) which believes that development is best understood by examining one's context. It states that individuals'abilitytoreachtheirpotentialisdependentonreallifesituationsandopportunitiesintheenvironm ent. In addition, individuals better adjust and are more satisfied in environments that match their attitudes, values, goals and experiences, that is, they are more satisfied when there is a fitbetweenthemselvesandtheirenvironment(Schutheiss,Kress,Manzi\&Glasscock,2001).Beingcongruen $\mathrm{t}$ with parents on career matters reflects a fit between individuals and their environment which likely facilitate and fosters career development (Roundy, 2015). Incongruity or lack of fit on the other hand is a potential external barrier to career development (Schutheiss et al. 2001). The theory states that parents influence career development through interactions, relationships they have with their children. The more encouraging and nurturing these relationships, interactions and environments are, the better children will develop careers. Hence, the ecological theory helped understand how parental factors play in the career development of children with MIDs.

\subsection{Significance of the Study}

Findings may contribute to the knowledge gap on the role of parental factors in career development of their children with MIDs.

\section{LITERATURE REVIEW}

Ulrich, Frey and Ruppert (2018) conducted a study on the role of parents in young people's career choices in Germany. The study used the National Educational Panel Study (NEPS) from which cohort (SC4) was analysed by descriptive data statistics on various counselling offers. The study revealed that influence of parents on young peoples' career choices was greater than that of teachers or other sources. The 2018 study suggests strengthening parents' competencies for them to better assist their children make suitable career choices. What remained unclear was how parental factors play a role in the career development of children with MIDs.

Liu, et al. (2015) conducted a study on parental influences on career development of children in Mainland, China. The study used the interpretive phenomenological design to examine how Mainland Chinese parents influence the career development of their 5th grade children. Six super ordinate themes were identified from both the children and the parents' perspectives; responsibility to career curiosity, influence on gender stereotypes, emphasizing the importance of education, encouraging 
independent career decision making, providing opportunities for career interest development and mothers as role models. Unlike the 2015 study which focused on 5th graders, the current study focused on how parental factors plays a role in thecareerdevelopmentofchildrenwithMIDsaged 16 and above.

Mwaa's (2016) survey investigated the extent to which parental factors influenced career choices among form four students in Nairobi County, Kenya. A sample of 400 was randomly selected from a population of 27614 form four students who had enrolled for Kenya National Examination Council (KNEC) in 2016. Purposive sampling technique was used to sample the ten schools. Questionnaires were used to collect data. The Statistical Package for Social Sciences (SPSS) software and statistics used to analyse the data. Findings show that parental factors such as high educational level, parental occupation, parental values and expectations and parent-child relationships influence career choices of students in Nairobi County. The study recommends that parents, teachers and guidance teachers should take cognisance of the influence of parental factors. Though conducted in African, it did not focus on parents of children with MIDs and was a survey as opposed to a descriptive survey with a qualitative approach used in this study.

Chizangwe (2016) used a descriptive survey to investigate the influence of parents on the career choice of their children at the University of Zambia. The survey used a qualitative approach on asamplesizeof54 (27children\&27parents) selected using purposive and random sampling. Questionnaires, FGDs and semi-structured interviews were used to collect data. Quantitative data was analysed using the Statistical Package for Social Sciences (SPSS 20) and Microsoft excel to generate frequencies and percentages. Findings show that parents especially the educated ones guided their children on careers like: Teaching, Nursing, Business related, Army (soldier), Police Service orAgriculturerelated.FindingsshowthatGrade12results, availability of jobs and the level of education of parents influenced children's career choices. The study recommends that parents should emphasise on hard work and capabilities of their children. The 2016study sample comprised parents and their children without disabilities as opposed to the current one.

\section{Methodology}

\subsection{Research Design}

The study used the descriptive survey design which according to Sink ombo (2016) can be used to collect information about people's attitudes, opinions or habits or any variety of educational and social issues. The design was deemed suitable to describe how parental factors play a role in the career development of children with MIDs and it utilises elements of both quantitative and qualitative research methodologies (McCombes, 2020).

\subsection{Research Sites}

The study was conducted at Makanaka, Tinashe and Tariro (pseudonyms) skills training centres in Ndola, Chi samba and Kabwe, respectively where children with MIDs from across the country, are offered skills training.

\subsection{Population, Sample and Sampling Procedure}

The population consisted of all parents of children with MIDs, their children with MIDs, all lecturers, principals at the named centres and all Directors (skills training) from TEVETA. A sample of 100respondents:60parents, 30children, 6lecturers, 3Principalsand1Directorwasused.Consistentwith Hamed (2020), the study adopted purposive sampling to select the centres, children with both parents, principals and the Director. Simple random sampling was used to select children (actual sample) and lectures. Semi-structured interviews (parents), questionnaires (lecturers, Principals and the Director and FGDs (children) were used to collect data in line with McCombes, (2020). Other sources such as documentary studies were consulted. 
Role of Parental Factors in the Career Development of Children with Mild Intellectual Disabilities in Three Selected Skills Training Centres in Zambia

\subsection{Data Analysis}

Consistent with Montanye (2017), data analysis commenced in the field by categorizing qualitative data into emerging themes. Quantitative data was analysed using SPSS to generate tables, percentages and charts.

\subsection{Ethical Issues}

Ethical considerations such as; seeking permission from the university ethical committee, respondents' confidentiality and other basic research conventions as alluded to by Reinsk, (2018),were taken into consideration. All participants' identity was kept anonymous.

As away to validate and ensure reliability of results, the report was peer reviewed

\section{FindingS AND DiSCUSSION}

\subsection{How Educational Levels of Parents Play a Role in the Career Development of Children with MIDs}

Findings showed that the educational levels of parents played a role in career development of children with MIDs through different ways as reflectedinfigure1.

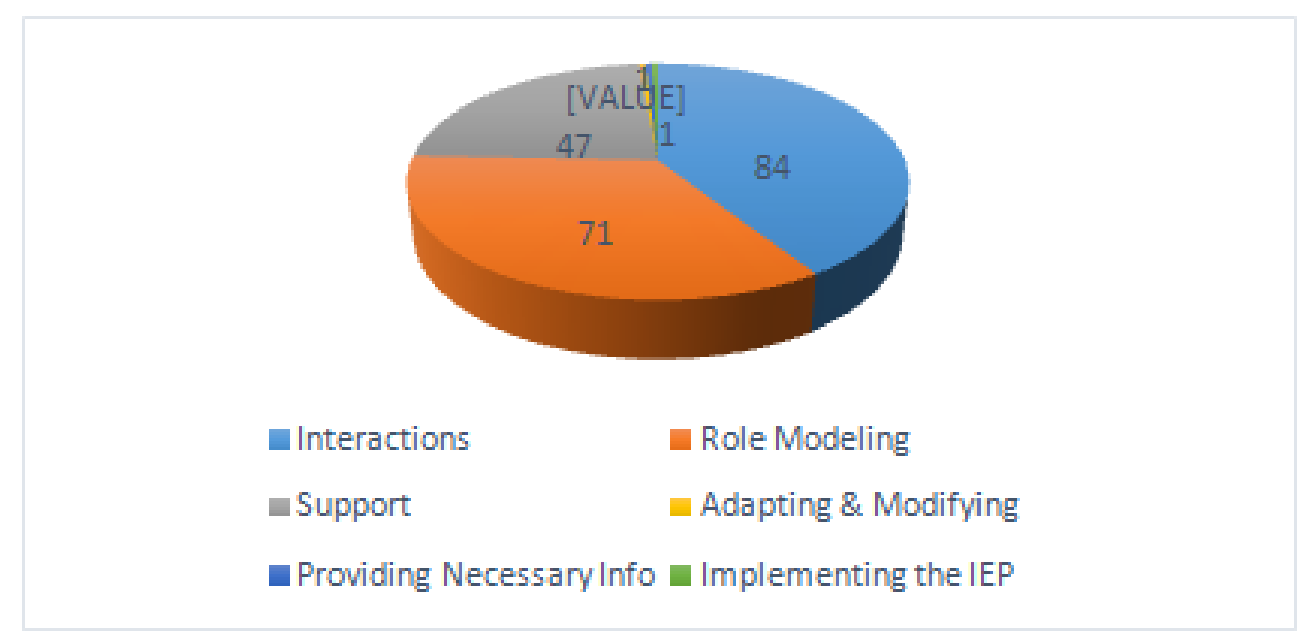

Figure1. How Education Levels of Parents play a role in the Career Development of Children MIDs

\subsubsection{Through Interactions}

Encouragements: From the findings, $84 \%$ of the respondents said that the educational levels of parents played a role in the career development of children with MIDs through interactions such asencouragements, advice, warningsandexplanations.38\% oftherespondentssaidthatparentstheeducation level helped parents to encourage their children in careers. Encouragements make children work hard in career activities they engage in and promotes learning and perseverance (Waters, 2019).These children later build determination and confidence to do better. This finding mirrors those of Liuet al. (2015) and Halim et al. (2017) found that parents encouraged children in their training. Hence without encouragements, children with MIDs may be at risk in their career pursuits. This shows that these parents believed that academic performance directly playsa role in the future of their children by opening up opportunities. As parents encouraged their children, they linked education to better later life making children develop the desire to work later. Likewise, Liu et al. (2015) asserts that children listen and believe in what their parents view as important (academic success as key to occupational success).This suggests that the environment of an individual shapes his or her career development. Findings show that parents with high educational levels (tertiary) had expectations on their children which made them offer encouragements. M27 had thisto say:

...because of my education, I understand the importance of education. .....I talk to my son about my education and my career. In addition, I encourage him because I know that he can do something after his training in. I know that due to his condition, he needs help that is why I encourage him...... 
This implies that expectations are a driving force for encouragements. Contrary to findings of Banks et al. (2016), parents of children with intellectual disabilities hold low expectations of children. As parents encourage their children they give feedback thereby motivating them. As rightly put by Hans (2012), parents should not only involve children in different activities but they should enrich those activities with stimulating interactions (encouragements) that trigger curiosity and exploration urge. This links the abstract concept of career development to something tangible, a career. Consistently, the ecological theory states that parental encouragements create nurturing environments suitable for career development of children (Roundy, 2015). The study therefore suggests that parents offer career talks long before school age. In addition, educators should equip such parents with appropriate career information. Regardless of low educational levels, some parents linked education to better life showing that such parents understood the value of education to their children's future lives. Respondent F04 shared:

\section{I ended in grade 9 my dear, I could not progress due to some reasons.... I know she does not admire me on that one ...I just encourage her to put effort in what she is doing....}

However, some parents never offered children encouragements. This finding contrasts those of Halim, et al., (2017) who found that adolescents were encouraged by their parents or caregivers in educational activities. This implies that these children were not stimulated to work hard and working roles were not embedded in their minds. The lack of encouragements thwarted children's possibilities of achieving in careers and it can be attributed to parental low expectations due to the disability (Chandramuki, Venkata\& Mysore, 2012). Respondent F18:

\section{.... As I indicated earlier on, am not yet convinced that children like my son can work and earn a living. I hear some work but I have never seen one....... It is difficult to believe... many people were I interact with say a lot of negative things about children of his condition...}

Although some parents said they offered encouragements, they were rarely at home. Respondent M28 said: I do encourage .... the only problem is that I am rarely home so..... Contrary to Literacy Changes Lives (2006), children spend 85 per cent of their time with their parents. This finding demonstrates an impoverished home environment which puts children at risk of developing and pursuing careers.

Advice: Findings show that $19 \%$ of the respondents said that some parents offer career advice to their children as a way of preparing them for the future. By nature, parents have beliefs and values about career success that constitute 'a good job' or 'ideal life' on which they base their advice. This helps children understand the relevance of working as an adult (Midkent, 2018) and it offers them opportunities to develop preferences and shape their conception of work. Since, children value what they are told by their parents (Ceka\&Murati, 2016), they internalise it there by developing careers. This finding indicates that children's conception of work begins at home. Consistently, the ecological theory believes that advising children on career matters creates a fit or congruence between the environment (parents) and children, fostering career development (Roundy,2015). However, findings show that even parents of low educational levels offer 'some' advice to their children. Respondent M05 had this to say:

\section{....I did not even finish school but am in business... Because of my low education level (secondary), I offer 'some' advice, but as for the types of jobs that he can do and other details, that is known by his trainers......}

The use of the word 'some' is an indication that the advice was not of quality. This is attributed to parents' low educational levels and lack of knowledge. It was however surprising that most children (73\%) did not indicate receiving any career advice, a cause to worry. The study suggests sensitising parents and providing them with career information so they can offer quality interest-based career advice.

Warnings: Findings from 13 respondents show that some parents of low educational levels use warnings in preparing their children for the future. Respondent F03 explained: 
Role of Parental Factors in the Career Development of Children with Mild Intellectual Disabilities in Three Selected Skills Training Centres in Zambia

I warn him against being playful and against not being serious with things...I never went far in education.... I ended at primary level (grade 7) .....

Even though warnings push children to work hard, their negative effects outweigh the positives. Warnings by nature instigate fear, creates anxiety and a fearful environment which according to the ecological theory, causes a poor fit or incongruence which inhibits career development. This finding demonstrates that although the same parents understand that education is critical for children's future lives, they lack good interactive skills. This demonstrates that the home environment constitutes the basic ecology where career development can be halted, altered or suppressed (Dishion\& Patterson,2006). Hence, the need for sensitisation of parents on the communicative power of words.

Explanations: It was clear from $30 \%$ of the respondents that parents of high educational levels (tertiary) prepare their children for the future through career explanations in which they link their education to employment and better livelihood. This helps children develop interest and map out their career paths. Respondent MC03-19 had this to say:

...Uuиuиuuuh, ....... My father says that him he is educated that is why he works... my father is a Police Officer...I also want to work like my father.........

Consistent with Bronfenbrenner's micro system, parents play a role in their off springs' occupational knowledge, values and career aspiration through explanations (Bryant, Zvonkovic\& Reynolds, 2009). Through explanations, employability skills, life roles and values are inculcated in such children. In turn, they understand the world of work, the responsibility of workers and became aware of the employment opportunities available. As such, if parents are not equipped with relevant interactive skills and career information (Muchalicek, et al., 2015), they may not execute valuable career explanations to their children. However, not all parents offered career explanations to their children with MIDs depriving them of opportunities to be listened to on their future lives. The failure can be linked to parents' low educational levels and poor parent-child interaction. In fact, responses from some children indicate low parent-child interactions. For example, respondent FC26 explained:

.....they do not normally talk about their education levels... both of them are rarely at home and even when they come back they don't say anything ....

Recent studies show that disability is associated with low levels of parent-child interactions (Banks et al., 2016) while low levels of parent-child interactions have been linked to parents' low educational levels. Although there has been some remarkable change of attitudes over disability, patches of negative attitudes towards disability among parents still exist (Nord, 2012) hence, the lack of career explanations by some parents. As such, parents should be helped to come into terms with MIDs to foster career development of their children.

\subsubsection{Through Implementing Individualised Education Plans of their Children}

Findings from a small number (1\%) show that parents play a great role in the implementation of the IEP of their children with MIDs. Respondent MD01 narrated:

The education level of parents has an influence on the career development of......Also the parents are able to implement the IEP that has been developed by the multidisciplinary team to foster career development.

A fundamental component of the Individuals with Disabilities Education Act (IDEA) is including parents as decision makers in their children's training. The rationale is that they advocate for their children's best interests. Parents' involvement in the training process increases the accountability of the IEP team and appropriateness of IEPs (Turnbull \& Turnbull, 1998). Parents are experts on their children with MIDs (Morse, 2017) and they have valuable information needed to write appropriate IEPsfor successful skill's training. Their engagement in the IEPs is widely accepted as a critical practice for supporting career development. The involvement ensures relationship building, understanding of school experiences and giving parents opportunities to have their voices heard in relation to their children's training (Underwood, 2010). 
Role of Parental Factors in the Career Development of Children with Mild Intellectual Disabilities in Three Selected Skills Training Centres in Zambia

\subsubsection{By Providing Information on their Children with MIDs}

Findings show that the education level of parents helps parents provide background information of their children. Respondent MD01 had this to say:

Parents also provide information on the child's strengths and weaknesses at home, background information on the child's history and development, and information on any family factors that may affect the child's learning and career development.....

As experts on their children, parents can share information on their children's strengths, weaknesses and interests and avail to team members the feelings expressed by their children about careers. They can indicate whether their children look forward to working or if they have some worries and what these worries are. Parents can indicate their thoughts about their children's successes and challenges showing what they think is going well and their concerns. Since they are custodians of information about their children's development or health they can also provide reports if any, from specialists. In addition, they can inform the team of any noticed changes, challenges, strategies or approaches including what they motivate their children to keep them on tasks, special equipment or supports required by their children.

\subsubsection{Through Role Modelling by Parents of Children with MIDs}

Findings from over half (67\%) of the respondents show that high educational levels (tertiary) makes parents inspirational. As these parents talk to their children on careers, they use themselves as examples. Through modelling, parents impart different attitudes and skills about occupations enhancing children's desire to pursue certain careers. Respondent FL02 explained:

...... educated parents and those in employment, are role models to their children.... they use themselves as examples... children value their parents so much so they admire whatever their parents do or are.... although they may not be able to understand what is involved in what they admire.....

Consistently, Eccles (2009) show that being a success in one's discipline makes one a model for his or her children. This shows that parents are the first role models of their children and that homes for such children had rich intellectual environments fit for career development. Hans (2012) also believes that being born to educated parents increases the likelihood of achieving a professional occupation. However, parents with low educational levels (primary or secondary) in this study were not inspirational to their children negatively affecting career development of their children. Respondent F03 also shared:

.....I am not that educated and .... I am not even a role model to him on education or career matters.... when talking to him. I just use other people who are educated and working as examples ....

Consistent with Hans, this indicates that the presence of parents with low educational levels impoverishes home environments, thereby inhibiting children's career development. Similarly, ecological theory believes that the home environment consists the basic ecology where career development can be suppressed, halted or inhibited (Dishion\& Patterson, 2006).

\subsubsection{Through Adapting and Modifying Home Environments}

Findings from $1 \%$ of the respondents show that educated parents do adaptation and modifying home environment helps children develop careers. Respondent MD01 explained:

...The education level of parents has an influence on the career development of children with intellectual disabilities because parents are able to adapt and modify the environment to foster child development and career development.

The home environment has a great role to play in children's career development when encouraging and supportive (Nyamwange, 2012) as it enhances positive self-esteem. When parents for example read and talk about careers and allow their children to do the same, they help their children. In addition, taking their children on career trips to industries or companies, parks or the aters provides 
children with informal enjoyable learning experiences for children. However, parents need to set career expectations for their children being mind ful of the limitations caused by intellectual disabilities, offering praise and encouragement where desirable. By setting routines that includes time limits which are monitored, children work with time. Furthermore, parents who limit children's number of after school activities and avail children with programs that depict careers help children develop careers. This suggests that centres should sensitise parents on various ways of making home environments fit for career development of their children.

It was however clear that lack of knowledge on intellectual disabilities and its career implications including low expectations put parents at low of helping their children develop careers. Respondent M05 narrated;

\section{... I do not have a lot of information on my son's condition to offer the needed career help. But whenever I have time, I explain to him that his training may help him work later... I offer 'some' advice, but as for the types of jobs that he can do and other details, that is known by his trainers...}

This finding demonstrates that the home environments for such children were impoverished, causing a poor fit or incongruence which according to the ecological theory negatively affects career development (Roundy, 2015). If parents are sensitised on attitude change, they may help their children develop careers, benefit from career options available and lead independent lives.

\subsection{How Occupations of Parents Play a Role in the Career Development of Children with MIDs}

Themes that emerged on how occupations of parents play a role in the career development of children with MIDs included role modelling and supporting children in careers.

\subsubsection{Through Role Modelling}

Findings from $45 \%$ of the respondents indicate that being inspirational helps children develop careers. As parents model admirable behaviour in the environment, they impart career attitudes, skills and confidence about occupations in their children with MIDs fostering the desire to work later. Respondent MC01-19 explained:

My father talks about his education, where he went to school and how he was passing. He says that is why he is working at the Ministry of Agriculture. When I finish I will also work in the Ministry of Agriculture. He encourages me to work hard....

Likewise, Ceka and Murati (2016), indicate that parents are the first role models for their children and have a strong influence on children's career development. Consistently, Liu et al. (2015) found that role models were individuals whose behaviours, styles and attributes were emulated by children. Through admiring their successful parents, children with MIDs develop the belief that they may also be successful in careers such as those of their parents. As argued by Eccles, (2009), if parents get satisfaction or a comfortable lifestyle from their jobs, children may admire and favour these careers over others. Similarly, Mathatha, (2013) and Liu et al.,(2017) found that children who admired a successful role model in a specific career were reported to have a preference for pursuing that same career. If parents fail to exhibit career-packed behaviours, they may thwart the career development of their children with MIDs.

Findings show that 12 children (male) out of 30 admired the occupations of their male parents proving Olaosebikan \& Olusakin's (2014) assertion that a father's occupation is highly correlated with his son's career choice. Consistently, Mathatha's (2013) study showed that children sought role models who were similar to them in an identifiable way such as physically, gender or race. This then suggests that parents who exhibit behaviours that communicate good attributes about their jobs, help their children develop careers. Interestingly, regardless of their impaired intellectual functioning, these children admired careers pursued by their parents without MIDs. Respondent F02 explained: 


\section{I have noticed that my daughter admires me and the work I do although she does not know details about it.... Added to this, the support I give her in her training encourages her to think of being employed like I am.}

Accordingly, Chandramuki et al. (2012) argue that despite their challenges, children with intellectual disabilities have some strengths. This finding demonstrates that role modelling is a strong predictor of children's career development. However, findings show that some parents were not inspirational, too busy or unavailable, impoverishing home environments, thereby inhibiting transmission of career knowledge. For example, respondent MC03-31 shared: .....my father is the one who works...... He is never home most of the time.... He goes for work.... Accordingly, the effectiveness of role models depends on the amount of time they spend with their children (Liu et al., 2015). This entails that the less the time these parents spend with their children with MIDs, the lesser the chances of their children developing careers. Moreover, such children have little exposure to available jobs, they rely on their parents (Nord, 2012), therefore, parents should be helped realise the importance of their presence in the home environment. According to the ecological theory, this finding indicates a poor fit or incongruence between children and their parents which hinders career development. This finding shows that the home environment constitutes the basic ecology where children's career development can be suppressed, halted, thwarted or hindered (Dishion\& Patterson, 2006).

The bio data shows that parents were in varying occupations implying varied role modelling, creating a rich career environment. On the other hand, the variations imply opposing role modelling that may be confusing to children. Similarly, Mwaa, (2016) argues that effects of varied role modelling can be negative or positive. Some parents expressed being role models in businesses. For example, respondent F04 had this to say: I can say I am a model of a hardworking mother, a business woman... Surprisingly, none of them said their children had interest in business and none of the children said they had wanted to do business. Yet, the Central Statistical Office (2012) reports that most children with intellectual disabilities were found in family businesses. This calls for the need to study around this area.

\subsubsection{By Supporting Children in Career Development of Children}

Findings from $29 \%$ of the respondents show that parents in inspiring careers were able to fully support their children with MIDs in career development while those that were not, struggled or did not. Most parents of tertiary education offer adequate support hence, education can be linked to inspirational occupations and better financial status.The support shows parentshave expectations regardless of the presence of mild intellectual disability. Contrary to Cosgrove, Mckeown, Travers, Lysaght, Nibroin and Archer, (2014), parents of children with intellectual disabilities are less likely to expect their children to go beyond school leaving certificate.An analysis of parents that neither sponsored nor adequately provided for their children show they were of low educational levels. Respondent F29 noted:I have a small business which allows me to provide 'something' for my daughter.....Such parents created impoverished home environments which according to the ecological theory hinders career development of children. Consistently, Hans (2012) argue that parents of lower income hold values that place their children with disabilities lowly and reflect less emphasis on occupational preparation. This demonstrates the need of forming support networks for parents of children with MIDs so as to help alleviate the financial stress.

\subsection{How Socioeconomic Status of ParentsPlays a Role in the Career Development of Children with MIDs}

Findings revealed that the socioeconomic status of parents plays a role in the career development of children with MIDs through role modelling, support and providing career information as depicted in figure 2 . 


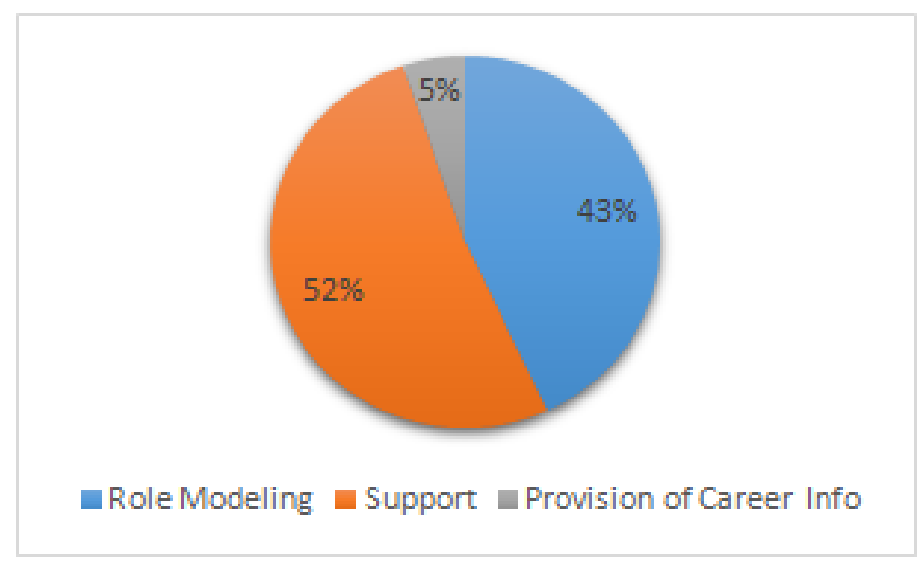

Figure2. How Parental Factors Foster Career Development of Children with MIDs

Source: Research findings, 2019.

\subsubsection{Through Child Support in Career Development}

It was clear from forty (40) respondents that high socioeconomic status of parents allows them to adequately support their children in career development. This support motivates children to work hard hoping to working later. M11 shared his views:

Although I am not in formal employment I am able to provide for my daughter.

The little support boosts her morale to think of her future life too.....

Although some parents offered support, most parents in this study were of low status and did not offer adequate support depriving children of the motivation to develop careers. Consistent with Humble and Dixon (2017), low socioeconomic status impacts negatively on motivation. This means that some homes were created out of economic strain and material hardship putting children at risk of career development. Worse still, parents of lower income hold low values on their children with disabilities (Hans, 2012) and tend to first direct resources to children without disabilities. Hence, if not addressed, this can significantly influence parental functioning and career development of their children. As pointed by Reich man et al. (2008), disability comes with challenges such as those of allocating funds for training children with disabilities. Therefore, parents should be sensitized that despite their challenges in performance, children with MIDs can and do go on to succeed into employment.

\subsubsection{Through Role Modelling}

Findings from thirty-five (35) respondents show that parents of high socioeconomic status inspire their children. Likewise, Ceka and Murati, (2016) states that parents are the first role models of their children and as they interact with their children on career matters, they use themselves as examples, thereby fostering career development of their children. However, parents of low socioeconomic status were not inspirational to their children hindering career development. Consistent with the ecological theory, this suggests that the home environment constitutes the basic ecology where children development can be suppressed (Dishion\& Patterson, 2006).

\section{CONCLUSION}

Although parental factors have the ability to foster career development of children with MIDs, lack of interactions, lack of support, lack role models, low expectations and low knowledge levels prevalent among parents. This are attributed educational levels, negative attitudes, lack of sensitisation or awareness.

\section{RECOMMENDATIONS}

Skills training centres should help parents form or join support groups for them to share experiences and acquire information that would increase their knowledge base on intellectual disabilities. The MoHE in collaboration with the Ministry of Health (MoH) and the Ministry of Community Development, Mother and Child Health (MCDMCH) should sensitise society on mild intellectual disabilities and its educational implications. 
Role of Parental Factors in the Career Development of Children with Mild Intellectual Disabilities in Three Selected Skills Training Centres in Zambia

\section{REFERENCES}

[1] Banks, J., Maître, B., McCoy, S. \& Watson, D. (2016). Parental educational expectations of children with disabilities. RESEARCH SERIES.

[2] Beirne-Smith, M., Patton, J.R. \& Kim, S.H., (2006). Mental Retardation: An introduction to intellectual disabilities ( $7^{\text {th }}$ ed.). Upper Saddle River (NJ): Pearson Merrill Prentice Hall.

[3] Bronfenbrenner, U. (1999). Ecology of the family as a context for human development. Research perspectives. Developmental Psychology, 22, 723-742.

[4] Bryant, B.K., Zvonkovic, A.M. \& Reynolds, P. (2006). Parenting in relation to children and adolescent vocational development. Journal of Vocational Behaviour, 69, 149-175.

[5] Ceka, A. \&Murati, R. (2016). The role of parents in the education of children. Journal of Education and practice, 7(5), 61-64.

[6] Central Statistics Office (2012). 2010 Census of population and housing. National Analytical Report. Vol 11. Lusaka: CSO.

[7] Chandramuki, I. Venkata, K.S., \& Mysore, N.V. (2012). Attitudes of parents towards children with specific learning disabilities, 23(1), 63-69.

[8] Cosgroove, I.C.,Mckeown, J., Travers, Z., Lysaght, O., NiBhrion, C.\& Archer, P. (2014). Educational experiences and outcomes on children with special education needs. A second analysis of data from the growing up Ireland study. Trim: NCSE.

[9] Dishion, T. J. \& Patterson, G. R. (2006). The development and ecology of antisocial behaviour in children and adolescents. In: Ciccheti, O. Cohen, D. J. (Eds.), Developmental Psychopathology, 3, 503-541. Wiley Hoboken, NJ. USA.

[10] Doren, B., Gau, J.M. \& Lindstrom, L.E. (2012). The relationship between parent expectations and postschool outcomes of adolescents with disabilities. Exceptional Children, 79(1), 7-23.

[11] Durisic, M. \&Bunijevac, M. (2017). Parental involvement as an important factor for successful education. GEPS Journal 7(3), 137-153.

[12] Eccles, J. (2009). Influence of parent's education on children's educational attainment: The role of parents and children perceptions. London Review of Education, 3(3), 191-204.

[13] Elham, D., Siti, N.Y., Rumaya, B.J. \&Mansor, A.T. (2012). Relationship between parenting styles and academic achievement in Sirjan. Malaysia. Asian Society Science, 8(1), 156-160.

[14] Halim, L. Rahman, A.N., Zimiri, R. \& Mortar, 1. (2017). The roles of parents in cultivating children's interest towards science learning careers. Kasestart Journal of Social Science, 30, 1-7.

[15] Hans, (2012)Hans, C.L. (2012). Parental involvement. Starting Strong III. Parris: OECD

[16] Humble and Dixon (2017),Humble, S. \& Dixon, P (2017). The effect of the schooling, family and poverty on children's attainment, potential and confidence from Kinondoni Dar eslaam, Tanzania. Journal of education and Research, 83, 94-106.

[17] Literacy Changes Lives (2006)Literacy Changes Lives: RochdaloBoragh Literacy Policy (2006). Rochdale: Rochdale Council.

[18] Liu, J., MacMahon, M. \& Watson, M. (2015). Parent influence on children development in Mainland, China. A qualitative study.http://doi.org/10.1002/j.2161-0045 Visited 01/06/18.

[19] Mathatha, V. (2013). Career development of learners with visual impairments: A case of Lions and Magwero schools for the blind. Unpublished Masters' Dissertation. Lusaka: University of Zambia.

[20] Ministry of Education (1996). Educating our future. Lusaka: Zambia Educational Publishing House.

[21] Morse, A. (2017). Parents' role in the individual education plan. SEAC

[22] Muchalicek, W., Lang, R. \&Raulston, J.T. (2015). Training parents of children with intellectual disabilities: trends, issues and future directions. intellectual disability. Curriculum Development Report, 2 , 110-118.

[23] Mwaa, M.A. (2016). Parental factors influencing career choices among high school students in Nairobi County. Unpublished Research Project.

[24] Nord, D. (2012). People with disabilities in America's work force: Time for fresh thinking. Impact, $25,1$.

[25] Olaosebikan, O.I. \&Olusakin, A. (2014). Effect of parental influence on adolescents' career choice in balladry local government area of Lagos State, Nigeria. Journal of Research and Methods in Education, 4, 44-57.

[26] Reichman, N.E., Coorman, H. \& Norman, K. (2008). Impact of children disability on the family. Maternal and Children Health Journal, 12(6), 679-683. 
Role of Parental Factors in the Career Development of Children with Mild Intellectual Disabilities in Three Selected Skills Training Centres in Zambia

[27] Roundy, (2015). Roundy, L. (2015). Bronfenbrenner's ecological systems.www. Citethisformcom/Topic. Visited 09/05/2018.

[28] Schultheiss, D.E.P., Kress, H.M., Manzi, A.J. \&Glasscock, M.J. (2001). Relational influences in career development: A qualitative inquiry. Counselling Psychologist, 29(2), 214-239

[29] Underwood, (2010).Underwood, K. (2010). Exceptionality Education International Vol 20 (1), 18-27.

[30] Waters, (2019). Waters, L. (2018). Parents and family. UC Berkeley’s GGSC http://greatergood.berker. Visited 01/07/19.

[31] World Health Organisation (2015). http://www.who.int.mental-health/evidence/atlas-id. Visited $12 / 09 / 2018$.

\section{AUTHORS' BIOGRAPHY}

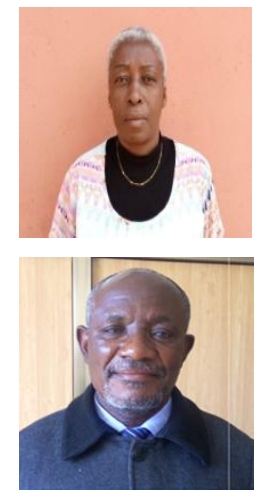

Viola Mathatha, has 28 years of teaching experience. She taught at Primary (Special Unit), Secondary, College and University levels. Currently, she a lecturer at Zambia Institute of Special Education in the Department of Learning Disabilities. Of late, her research and publications have mostly focused on career development of children with disabilities.

Prof. LufeyoChitondo, currently Registrar at Rockview University in Lusaka, has been a Primary school, Special Education and secondary school teacher as well as College and University lecturer. He has held positions of Head of Department, Deputy Head Teacher, Head Teacher, Education Standards Officer and District Education Board Secretary. Prof. Chitondo has 39 years teaching experience and is a lecturer of Languages and Educational Research.

Citation: Viola Mathatha, Professor Lufeyo Chitondo. "Role of Parental Factors in the Career Development of Children with Mild Intellectual Disabilities in Three Selected Skills Training Centres in Zambia" International Journal of Humanities Social Sciences and Education (IJHSSE), vol 8, no. 8, 2021, pp. 164-175. doi: https://doi.org/10.20431/2349-0381.0808016.

Copyright: () 2021 Authors. This is an open-access article distributed under the terms of the Creative Commons Attribution License, which permits unrestricted use, distribution, and reproduction in any medium, provided the original author and source are credited. 